ENTRE PROFESSORES E MESTRES:

\title{
O RPG E AS EXPERIÊNCIAS DOCENTES NO ENSINO DE HISTÓRIA ${ }^{1}$
}

\author{
BETWEEN TEACHERS AND DUNGEON MASTERS: \\ RPG AND TEACHING EXPERIENCES IN HISTORY TEACHING
}

Brunno Manoel Azevedo Pessôa ${ }^{2}$

\begin{abstract}
RESUMO: É crescente a quantidade de pesquisas acadêmicas no ensino de história que se dedicam a pensar a prática docente. No que diz respeito ao RPG enquanto linguagem no ensino de história, apesar do significativo crescimento e popularização do jogo aplicado à sala de aula e das pesquisas que se dedicam a analisar sua efetividade no processo de ensino-aprendizagem, existem poucos materiais de referência que orientem os docentes de história na elaboração de suas próprias experiências de aula-aventura de RPG, mantendo a prática ainda restrita em sua grande maioria aos profissionais que já conhecem o jogo ou que de alguma forma tiveram contato com ele durante sua formação. O objetivo deste trabalho é apresentar algumas considerações a partir da experiência docente no que diz respeito a iniciativas com o uso do RPG em aulas de história, através de entrevistas com professores, investigando as características dos mesmos, suas especificidades e diretrizes para a elaboração de suas aulas-jogo.
\end{abstract}

Palavras-chave: Ensino de história. Experiência docente. RPG.

\begin{abstract}
There is a growing amount of academic research in teaching history that is dedicated to thinking about teaching practice. Regarding RPG as a language in history teaching, despite the significant growth and popularization of the game applied to the classroom and of the researches that are dedicated to analyze its effectiveness in the teaching-learning process, there are few reference materials that guide teachers of history in the elaboration of their own experiences of class-adventure of RPG, keeping the practice still restricted in its great majority to professionals who already know the game or that somehow had contact with him during his formation. The objective of this work is to present some considerations from the teaching experience regarding initiatives with the use of RPG in history classes, through interviews with teachers, investigating the characteristics of the same, their specificities and guidelines for the elaboration of their class-game.
\end{abstract}

Keywords: Teaching of history. Teacher experience. RPG.

1 Artigo produzido sob o fomento da CAPES durante realização de pesquisa de Mestrado, entre 20152018.

2 Mestre em História Social da Cultura pela Universidade Federal Rural de Pernambuco - URFPE. Contato: apbrunno@gmail.com ORCID https://orcid.org/0000-0003-1224-3256 


\section{Introdução}

Este artigo é fruto de pesquisa desenvolvida entre 2015 e 2018 onde foram investigados os modos em que professores de história utilizavam o jogo de RPG ${ }^{3}$ como recurso para o ensino da história, executada durante minha atuação enquanto bolsista CAPES no curso de mestrado em História Social da Cultura Regional da UFRPE. Esta pesquisa por sua vez retomou, em certa medida, estudos prévios realizados durante os anos de graduação como Bolsista do PIBID $^{4}$ com alunos da rede pública da cidade do Recife.

A perspectiva desta pesquisa anterior foi permitir aos estudantes participantes do projeto um protagonismo na produção do conhecimento, ao desenvolverem jogos de RPG que pudessem auxiliar enquanto metodologia para o ensino da história a partir de suas próprias necessidades. Os conteúdos eram selecionados e eram desenvolvidos jogos interativos pautados em narrativas orais compartilhadas, resultante comum do jogo de RPG e sua mecânica.

Dessa forma o jogo propicia o exercício da criatividade e das capacidades de expressão e socialização através da necessidade de trabalho em grupo; o estímulo à leitura e a pesquisa para a elaboração de personagens, cenário, enredo; conhecimentos em linguagens, história, geografia, matemática e tantas outras áreas do conhecimento, fazendo deste algo interdisciplinar; além de possibilitar uma formação crítica e reflexiva ante a simulação de determinadas situações que estimulam o raciocínio ético e humano.

Na contramão desse raciocínio, o que pude atestar durante o período de pesquisa é que no tocante ao ensino da disciplina escolar de história no Recife existe uma resistência quanto à incorporação de linguagens outras que não as mais tradicionais formas de ensino. Resistência esta que quando não nega o uso dessas linguagens, carece de qualificação ao propor a utilização destas novas fontes e formas de produção de conhecimento sem o devido preparo ou reflexão quanto a sua prática. Segundo Selva Guimarães Fonseca (2003), ao explicitar suas considerações sobre o uso de novas fontes no ensino da história, os saberes

3 Roleplaying Game, traduzido como "jogo de interpretação de personagens".

4 Programa Institucional de Bolsas de Iniciação à Docência.

História \& Ensino, Londrina, v. 26, n. 2, p. 337-356, jan./jun. 2020 
disciplinares são rearticulados numa busca por uma legitimidade da realidade histórica, onde professores e pesquisadores precisam se apropriar de diferentes linguagens, suas possibilidades e desafios.

A partir dessa premissa, para a pesquisa de mestrado foi realizado um levantamento bibliográfico das produções acadêmicas, no tocante a dissertações e teses, na busca pela identificação de pesquisas que assumissem a linguagem do RPG aplicada ao ensino da disciplina escolar de história. Foram encontradas, em âmbito nacional, apenas quatro trabalhos que se dedicam especificamente as investigações quanto ao uso do jogo de RPG no ensino da história. Trabalhos estes que foram publicados entre os anos de 2008 e $2014^{5}$. Não foram levados em consideração aqui os trabalhos publicados após o ano de 2015.

Desse levantamento inicial foi possível identificar que apenas dois dos trabalhos encontrados, os de Ricardo Jefferson da Silva e Joycimara de Morais Rodrigues apresentavam perspectivas sobre a elaboração das aulas utilizando o RPG que pudessem ser exercidas por outros professores. Em suas produções foi possível perceber orientações para o desenvolvimento de cenários, para a escolha de sistemas de jogo e a criação de ambientações, que são algumas das características que constituem a prática do RPG, porém de forma pontual e esparsa, sem se dedicar em esforços que não fossem os de seus próprios objetos de análise.

Diante dessa realidade encontrada na produção acadêmica foi extraído o problema que norteou a pesquisa do mestrado: a escassez de pesquisas e produções que abordam com profundidade a elaboração de práticas pedagógicas com jogos de RPG para o ensino da disciplina escolar de história.

A partir da problemática central foi delineado enquanto objetivo principal da pesquisa de mestrado a criação de um modelo teórico-metodológico para o desenvolvimento de estratégias de ensino que utilizem a linguagem do jogo de RPG enquanto recurso pedagógico para a disciplina escolar de história. Porém, um problema surgiu a partir dessa premissa: como poderemos elaborar esse referencial? De que forma seria possível estabelecer os parâmetros teóricos e metodológicos desse fazer docente?

5 A saber, em ordem cronológica: Cardoso (2008), Pereira (2010), Francisco (2011) e Rodrigues (2014). 
Foram com essas questões que, no momento da banca de qualificação do texto inicial da dissertação, ao deparar-se com a impossibilidade de realizar esse levantamento ante a ausência de espaços que permitissem a análise da prática docente, foi feita a opção pela investigação da experiência de docentes que já tivessem utilizado a linguagem do RPG como recurso para as aulas de história através de suas narrativas, dos seus relatos de experiência.

É perceptível também que, assim como o RPG se constrói narrativamente, a construção do conhecimento histórico está intimamente ligada à elaboração de narrativas. Segundo Mario Carretero e José Castorina (2012, p. 223) "nós, seres humanos, interpretamos narrativamente tanto as nossas ações e comportamentos quanto as dos demais; existe, portanto, uma predisposição a organizar esta experiência em estruturas de tramas".

O RPG, enquanto estimulador de experiências narrativas, funcionaria como um espaço de catarse onde o professor que se propor narrador poderia transformar conhecimentos com o intuito de criar formas de significação do passado. Entendemos então o ensino da disciplina de história através do RPG como uma possibilidade de mudança conceitual, e tomamos como referência principal o papel transformador de sua prática ao reorganizar a construção do saber histórico escolar, no intuito de não apenas desenvolver conteúdos e habilidades considerados importantes, mas em formar e transformar a própria concepção sociopolítica daqueles envolvidos na experiência lúdica que é o jogar RPG.

Metodologicamente, a pesquisa então se identificou enquanto híbrida, pois trata da produção de um conhecimento e da didática de uma disciplina. Para dar conta de tal complexidade, a proposta metodológica se faz igualmente híbrida: por sua natureza histórica, busca através do procedimento de análise bibliográfica a comparação e delimitação de um campo, explorando os limites e possibilidades da experiência docente na escola e da didática da história enquanto ramificação específica do saber histórico; e por sua natureza educacional, uma abordagem aplicada através de um método hipotético dedutivo, pois constrói uma hipótese teórica em relação a uma ferramenta metodológica para o ensino da história.

Para a elaboração do modelo referencial proposto na pesquisa de mestrado que deu origem a este artigo, foi preciso analisar como os professores entrevistados se identificavam com o exercício do jogo de RPG, e como esses 
elementos se expressavam em suas práticas. Tendo em foco a experiência dos docentes que utilizaram a linguagem do RPG no ensino da disciplina de história em salas de aula da educação básica, a metodologia escolhida para a coleta dos dados e sua posterior análise foi a das entrevistas.

Este artigo trata então desta etapa da pesquisa: as entrevistas realizadas com os docentes que foram identificados e selecionados dentre os que utilizaram o RPG no ensino de história nos últimos anos (2015-2017) em Recife-PE e que se dispuseram a participar da mesma, bem como as narrativas coletadas a partir do projeto de entrevistas, onde foram definidos os objetivos e métodos que seriam aplicados à coleta dos relatos.

Tendo como objetivo a construção de um modelo referencial teórico metodológico para o desenvolvimento de estratégias de ensino a partir da linguagem do jogo de RPG, a análise dessas entrevistas buscou explicitar, no âmbito da experiência docente, os elementos que constituem o jogo e as peculiaridades de sua prática, bem como uma série de orientações a professores de história que tenham o interesse em elaborar suas próprias aulas utilizando essa linguagem.

\section{Utilizando entrevistas como técnica de coleta de dados}

No processo de definição metodológica, durante a pesquisa realizada, partimos da premissa de que a pesquisa de cunho qualitativo tem como base a análise da subjetividade de um fenômeno, de sua interpretação, onde através da coleta de dados e informações dos sujeitos envolvidos e de sua interação com os processos investigados é possível compreendê-los (MALHEIROS, 2011, p. 188). Estabelecendo as questões ou o foco de interesse, o pesquisador em contato com os sujeitos "constrói o quadro teórico aos poucos, à medida que coleta os dados e os examina" (GODOY, 1995, p. 63)

No que diz respeito à coleta dos dados analisados, a técnica de entrevistas foi escolhida por sua abordagem aproximada com os sujeitos e fenômenos investigados. Quando falamos das entrevistas compreendemos que estas se caracterizam por um conjunto de procedimentos técnicos que tem início na elaboração de um projeto (o projeto de entrevistas) que compreende encontros 
planejados com os sujeitos investigados, onde os relatos exercidos de maneira dialógica são gravados em diferentes formatos e mídias, que por sua vez são passados do código oral para o escrito e posteriormente validados pelos sujeitos envolvidos (MEIHY; RIBEIRO, 2011, p. 12-13).

Compreendemos que esta metodologia possui em sua execução especificidades que atenderam a proposta da pesquisa de forma singular, pois não apenas possibilitou que através das entrevistas diretas fosse possível ter acesso às experiências dos docentes, como também permitiu a análise da experiência dos mesmos a partir de uma abordagem mais subjetiva, onde buscou-se compreender as impressões que os docentes fazem de si mesmos e como essa perspectiva pôde indicar caminhos e inferir nos processos presentes em sua própria formação acadêmica e seu papel enquanto professor.

Nesse contexto, devido a esta abordagem mais aproximada aos atores investigados, a adoção das entrevistas enquanto técnica de pesquisa tornou-se uma iniciativa de valorização da experiência docente, pois através do registro de seu relato se intencionou dar visibilidade a uma categoria profissional (professores) e a uma disciplina escolar (história) que cada vez mais sofrem com o descrédito da sociedade, especialmente após as recentes mudanças propostas na educação brasileira que retira a obrigatoriedade do ensino da disciplina escolar de história no ensino médio (BRASIL, 2016, p. 1) bem como o avanço de movimentos ideológicos de combate aos professores e ao ensino plural e democrático (MOURA, 2016, p. 22)

O ponto de partida para a análise das entrevistas foi a elaboração de um perfil dos professores entrevistados, pois nos permitiu assim compreender as especificidades de sua formação e experiências. Identificadas estas características, pudemos verificar como elas influíram no processo de elaboração da metodologia utilizada na aplicação dos jogos de RPG nas salas de aula de história.

Toda proposta de análise que faz uso das entrevistas deve partir de um projeto. De fato, Meihy e Ribeiro (2011, p. 13) afirmam que a entrevista configura uma sistematização dos processos organizados pela lógica proposta no projeto inicial. Logo, não é sem sentido a afirmação de que a ausência de um projeto impossibilitaria a existência da pesquisa. Ainda em acordo com os autores, todo 
projeto de entrevistas deve funcionar como um guia da pesquisa que se pretende realizar, e para tanto ele prevê determinadas etapas, como apontadas abaixo:

1. Planejamento na condução das gravações segundo indicações previamente feitas;

2. Respeito aos procedimentos do gênero escolhido e adequado de história oral;

3. Tratamento da passagem do código oral para o escrito, no caso da elaboração de um texto final para a pesquisa ou escritura de um livro;

4. Conferência da gravação e validação;

5. Autorização para uso;

6. Arquivamento e/ou eventual análise;

7. Sempre que possível, publicação dos resultados em: catálogos, relatórios, textos de divulgação, sites, documentos em vídeo ou exames analíticos como dissertações ou teses. (MEIHY; RIBEIRO, 2011, p. 13).

No caso, uma entrevista se configura enquanto meio quando é parte de um processo maior que compreende a produção de um documento a partir do registro oral, que será posteriormente analisado no intuito de garantir sentido ao que foi registrado. Enquanto parte de uma pesquisa acadêmica, esse processo é essencial para a elaboração de um texto crítico ou analítico. A perspectiva objetivada na pesquisa de referência, para garantir maior legitimidade às indicações de procedimentos metodológicos propostos a partir da prática docente dos entrevistados, pressupôs uma análise cruzada com uma bibliografia selecionada no que diz respeito ao uso dos Roleplaying games no ensino da disciplina escolar de história.

No caso, foi escolhido um texto acadêmico que nos serviu de base referencial para a análise comparativa das entrevistas: a dissertação de mestrado de Ricardo Jefferson Francisco da Silva. A escolha deste trabalho acadêmico seguiu alguns critérios. Primeiro, diante das poucas produções no tocante a dissertações e teses que abordavam especificamente o uso do RPG no ensino da disciplina de história disponíveis ${ }^{6}$, este texto à época da pesquisa, era o estudo mais recente sobre a prática do RPG em salas de aula de história.

Em segundo aspecto, a pesquisa foi a única encontrada que teve como foco da análise as experiências do jogo em sala de aula obtida com a intervenção do

6 ver nota de rodapé n. 4 , p. 2. 
próprio pesquisador: no caso de Ricardo ao analisar a experiências de alunos do ensino fundamental ao aplicar uma aventura de RPG enquanto metodologia com tema de história do Brasil Colonial para uma turma do sétimo ano do ensino fundamental em um Colégio Estadual da cidade de Londrina - PR.

É importante lembrar também que a finalidade da pesquisa, ou o lugar ao qual ela pertence e se destina, no que diz respeito ao uso dos relatos de experiência coletados também é importante na concepção de um projeto de entrevistas. As características implícitas em um projeto se alteram a depender desta finalidade: se a pesquisa atende a alguma comunidade, alguma necessidade acadêmica, alguma empresa, etc. A proposta de pesquisa deste texto, por exemplo, destina-se a fins acadêmicos o que exige:

Fundamentação teórica apurada, procedimentos operacionais justificados, eventuais diálogos historiográficos, inscrição nos diálogos intelectuais e avaliação da fortuna crítica, tudo somado se abraça para fazer da história oral intelectual ou acadêmica uma modalidade capaz de promover explicações que se enquadram nos critérios de superação das experiências anteriores (MEIHY; RIBEIRO, 2011, p. 48).

Logo, buscou-se compreender o entrevistado não apenas como uma fonte de pesquisa, mas sim como um agente que trabalha em conjunto com o entrevistador numa relação definida pela ética e pela valorização do papel dos sujeitos envolvidos no processo compartilhado, que é o ato da entrevista em si. Segundo Meihy e Ribeiro (2011, p. 21), o papel de fonte neste tipo de pesquisa cabe ao registro gravado e a sua validação na decodificação/ transformação do texto oral em texto escrito, uma vez que este é legitimado por aqueles que participaram do processo.

No caso, houve certa dificuldade em definir quais seriam os agentes nesta etapa da pesquisa, pois poucos foram os docentes identificados que já haviam aplicado o RPG em sala de aula e que tivessem disponibilidade para participar da etapa das entrevistas.

Contudo, dois docentes decidiram contribuir com suas experiências neste processo. Seus dados foram ocultados por questões de privacidade: o primeiro, chamamos de Entrevistado 1, é um professor que já fazia uso do RPG no ensino da história, inclusive com pesquisa e produção acadêmicas próprias sobre o tema; 
e o segundo, o Entrevistado 2, é docente recém graduado que desenvolveu projeto de pesquisa através do PIBID/UFRPE com o uso dos RPGs no ensino de história, e atuou em sala de aula como professor durante sua formação.

Definidos assim os colaboradores, a etapa seguinte foi a da elaboração do projeto de entrevistas em si, que foi pautado na esquemática apresentada previamente. De início, vale salientar que esta etapa foi crucial ao processo de entrevistas, pois foi através do projeto de entrevistas que os agentes colaboradores tiveram acesso ao que se pretendeu com a sua contribuição. Neste projeto foram descritos os objetivos da entrevista, como ela se enquadrou dentro do processo de pesquisa e a composição do questionário a ser aplicado, um roteiro especificando os caminhos pelos quais a entrevista pretendeu enveredar durante a coleta do registro gravado.

Meihy e Ribeiro (2011, p. 28) afirmam também que para realizar a entrevista é preciso seguir certos procedimentos criteriosos, onde no projeto precisam ser respondidas as seguintes perguntas: "Quando?", "De quem?", "Como?" e "Porquê?" No caso da pesquisa aqui mencionada, coube inferir sobre a existência destes critérios dentro do que eles se propuseram. Dentro desta perspectiva o projeto de entrevistas precisou também identificar suas condicionantes, de que maneira os procedimentos seriam realizados, a saber: se a entrevista se destinaria a grupos ou indivíduos, quais os objetivos da entrevista, se o roteiro da entrevista compreendeu as especificidades da pesquisa que se pretendeu fazer e qual o corpus documental que fez parte da análise das entrevistas. Todas estas características fizeram parte deste processo de elaboração de um projeto de entrevistas.

No caso do referente projeto, os registros foram, respectivamente: entrevistas individuais, com o objetivo de registrar as experiências docentes com o uso do RPG no ensino de história para a elaboração de um modelo que serviria de referencial teórico-metodológico para professores de história. O roteiro de perguntas da entrevista foi elaborado a partir do levantamento bibliográfico realizado, onde um dos trabalhos encontrado foi utilizado como parte do corpus documental, como citado anteriormente.

Definidas essas condicionantes, a pergunta "Quando?" refere-se ao sentido que se deseja dar ao projeto. No caso desta pesquisa, o quando é a razão inicial 
que nos trouxe ao uso das entrevistas como fonte a ser analisada. O que se buscou de início foi a capacidade de preencher lacunas referenciais presentes nos trabalhos acadêmicos na área do ensino de história que, ao utilizar o jogo de RPG como método de ensino da disciplina, não se detiveram em especificidades da prática docente.

No que tange o "quem", também identificamos parte dos objetivos da pesquisa: realizá-la com professores de história que aplicaram o RPG como metodologia no ensino da história em salas de aula de Recife-PE. Portanto, para a elaboração do projeto de entrevistas foi preciso considerar todas as etapas que fizeram parte de uma iniciativa maior, que consideramos como a própria razão política e transformadora existente no ato da pesquisa docente: possibilitar mudanças através da valorização do protagonismo dos professores.

\section{Experiências docentes e o jogo de RPG}

O nosso primeiro entrevistado é graduado em Licenciatura Plena em História pela Universidade Federal Rural de Pernambuco e Mestre em Educação pela Universidade Federal de Pernambuco. A época da entrevista, o Entrevistado 1, lecionava em uma escola privada em Recife-PE, mas já contava com uma vasta experiência enquanto docente, pois desde o início de sua formação acadêmica atuou como professor de história em diferentes instituições de ensino:

Dentro desse período passei por algumas instituições, todas elas privadas. Minha experiência em sala de aula é com a educação privada, embora tenha algumas poucas experiências, não como docente, mas em outras situações, em outras conjunturas, na educação pública (ENTREVISTA 1, 2017, p. 114).

Como afirma acima, o Entrevistado 1 possui uma experiência diversificada no que diz respeito a origem das instituições de ensino que atuou, sejam públicas ou privadas, e seus diferentes contextos. Essa afirmação é interessante do ponto de vista da experiência do docente ao utilizar o RPG enquanto recurso para o ensino da história pois configura uma relação com um ambiente escolar específico, que são as instituições privadas de ensino, e como esta característica de sua atuação 
pode ser significante no que foi determinante para as escolhas metodológicas feitas por ele no uso desta linguagem.

Nosso segundo entrevistado também é graduado no curso de Licenciatura Plena em História pela UFRPE. O professor possui uma trajetória relativamente diferente pois participou do Programa de Bolsas de Iniciação à Docência, o PIBID, durante sua trajetória acadêmica. Como relata o entrevistado:

Eu acabei de me formar em 2016.2 e também eu estou nessa área do ensino de história pesquisando sobre o RPG e ensino de história com a professora L.F.. E é isso, minha monografia foi sobre isso também [...]. Eu fui para um evento na UFPE, acho que isso aí eu estava no meu primeiro período, e lá que eu vi que eu podia fazer esse link entre um hobby meu e a minha profissão. [...] Aí que eu vi que realmente é possível fazer esse link entre o RPG e o ensino, tem pessoas que fazem isso (ENTREVISTA 2, 2017).

O trecho acima citado faz referência a uma característica determinante para a compreensão da experiência de ambos os professores, enquanto docentes que utilizam os RPGs para fins pedagógicos: a formação acadêmica. No caso do Entrevistado 1, o professor se considera "ponto fora da reta" por só vir a conhecer o jogo de RPG após o início de sua formação. Quando questionado sobre o seu primeiro contato com o RPG o entrevistado relata:

Normalmente o pessoal que utiliza RPG na sala de aula era jogador anteriormente. E aí vai para a formação inicial e acaba utilizando o RPG na sala de aula. Eu sou ponto fora da reta porque eu não conhecia o RPG até minha formação inicial. Foi por conta de uma disciplina no curso de história em que eu tive o primeiro contato com o RPG, com o que é o RPG. Eu já estava na sala de aula após essa primeira experiência numa disciplina, a disciplina de Linguagens Alternativas no Ensino de História, ofertada pelo curso de história da rural [UFRPE], eu achei interessante a possibilidade de utilizar o RPG na minha prática docente [...]. Então a partir disso, acho que 2010, eu dava aula numa escola em São Lourenço da Mata, uma escola de bairro, e aí nessa escola eu trabalhava com alunos do sexto ao nono ano, e comecei a experimentar o RPG nas minhas próprias aulas. Mas a partir dessa experiência no curso de formação, do curso de formação inicia (ENTREVISTA 1, 2017).

O professor, no início de sua experiência com a linguagem do RPG, pode ser considerado então como "jogador não-sistemático". Compreendendo que os jogadores sistemáticos são os praticantes do RPG enquanto hobby de entretenimento (BATISTA; SALDANHA, 2009, p. 704), o professor desconhecia a 
existência do jogo até seu primeiro contato em uma disciplina durante sua formação docente. O Entrevistado 2, por sua vez já conhecia o jogo de RPG, sendo praticante do hobby desde o início da adolescência: "RPG eu jogo desde os meus treze anos de idade, eu estou com vinte e cinco agora, desde os treze anos eu jogo RPG." (ENTREVISTA 2, 2017), sendo então o professor um jogador sistemático de RPG. Essa é uma das características mais significativas no que diz respeito à experiência com o uso do jogo por docentes de histórias em sala de aula, pois apresenta determinantes importantes sobre as carências e exigências necessárias para o domínio do jogo e o desenvolvimento das experiências jogadas em sala por profissionais que estejam ou não familiarizados com o uso de sua linguagem.

Ainda sobre esta característica, é possível perceber ao longo da entrevista que certas escolhas teóricas e metodológicas são orientadas pelas necessidades encontradas nestas experiências distintas. Podemos relacionar, por exemplo, a forma como ambos os entrevistados definem as publicações ou os materiais de suporte que foram inicialmente necessários para o uso do RPG enquanto metodologia de ensino. Quando questionados sobre seus referenciais iniciais, eles nos dizem:

Para isso eu precisei fazer leitura teórica, alguns autores que já circulavam ali, entre a educação e a utilização do RPG em sala de aula, como o Alfeu Marcatto por exemplo. Depois me apropriar da linguagem do RPG, porque eu precisava conhecer sistemas de regras, como é que funcionava a ambientação, o contexto das aventuras, o que era um personagem, né? Alguns conceitos que são muito próprios do RPG (ENTREVISTA 1, 2017).

Primeiro foi Huizinga para dar [...] o que é jogo. E também críticos de Huizinga, é bom você ler críticos de Huizinga que ele fala algumas coisas ali que você realmente tem que criticar depois [...]. E Walter Benjamin. Já que o RPG é um jogo de narrativa, que para mim RPG é aquele jogo que você joga basicamente interpretando personagens em um contexto específico [...]. "O Narrador" do Walter Benjamin que também deu uma ampliada no conceito de narrador e de narrativa (ENTREVISTA 2, 2017).

Tomando por base os relatos acima podemos identificar que para o Entrevistado 1, por exemplo, que não conhecia o RPG anteriormente a sua formação inicial e teve seu primeiro contato com o RPG para finalidades pedagógicas, a maior necessidade de suporte teórico era a que permitisse a 
compreensão do que era o RPG, quais suas características, e quais as experiências já existentes sobre os RPGs voltados para o ensino, dado que ele expressa em diferentes momentos da entrevista, ressaltando autores e pesquisadores já conhecidos por sua produção acadêmica e bibliográfica.

Já o Entrevistado 2, que por sua vez já conhecia o jogo de RPG por praticálo desde a adolescência busca suporte em elementos teóricos distintos. Possivelmente por já conhecer as características do jogo, o segundo entrevistado faz referência a trabalhos que o ajudem na compreensão o RPG enquanto objeto da cultura de consumo e como seus elementos são interpretados historicamente, buscando dar sentido a características como a narrativa, a experiência e a imersão existentes no jogo.

Percebidas estas distinções entre os entrevistados é possível definir certos conceitos a serem utilizados nesta análise. Podemos classificar como "jogadores sistemáticos" aqueles que já tiveram contato com o RPG antes de sua formação inicial, como forma de entretenimento; e de "jogadores não-sistemáticos" todos os praticantes do jogo que tiveram um contato inicial com o RPG para outros fins que não os de entretenimento, como os professores que conheceram o jogo voltado ao ensino escolar. Vale ressaltar que para esta classificação consideramos "contato com o RPG antes de sua formação inicial" apenas para os que tiveram contato com os modos de jogo que produzem narrativas imagéticas em coletivo, que são o RPG de Mesa $^{7}$ e LARP ${ }^{8}$. Outras expressões do jogo como o RPG eletrônico, por exemplo, não são consideradas nesta classificação pois a experiência do jogo nesses casos ou é individual, ou é baseada em uma plataforma com roteiro e narrativa pré-definidos.

Estabelecida esta classificação, podemos retornar ao dado mencionado pelo Entrevistado 1, que se considera um "ponto fora da reta". O que seria de fato, essa reta? Ao se considerar um "ponto fora da reta" o entrevistado afirma estar ciente de sua condição enquanto professor que inicialmente não conheceu o RPG enquanto hobby, mas faz uso do jogo para fins pedagógicos. Para ele, a "reta"

7Chama-se Tabletop RPG, ou RPG de Mesa a versão mais tradicional do hobby, comumente jogada com os participantes envolta de uma mesa, que serve de tabuleiro para as rolagens de dados e anotações as fichas de personagem. Essa última também dá o nome do estilo de Pen and Paper $R P G$, RPG de Pena e Papel.

8Sigla para Live Action Role Play, traduzido como "Jogo de Interpretação ao vivo". 
seria um caminho comum aos jogadores e jogadoras de RPG que enveredam no exercício da docência: buscar incluir o hobby em sua prática docente, numa união entre o útil e o agradável, como diz o popular. Como citado anteriormente, o próprio entrevistado 2 , enquanto jogador sistemático, além de se enquadrar nesta definição deixa claro que de fato foi uma motivação inicial a união entre seu hobby e a sua prática profissional.

Apesar de expressar um elemento de significância para a compreensão desse caminho formativo e das diferentes características e desafios que se apresentaram para ambos os entrevistados, sejam jogadores sistemáticos ou não-sistemáticos, a possibilidade de que o uso do RPG pedagógico seja apenas um desejo estético de seus praticantes perde força, por exemplo, ao encontrar experiências como as do próprio Entrevistado 1, que escolheu fazer uso do jogo enquanto recurso pedagógico já na condição de docente devido aos benefícios e ganhos que a linguagem traz se utilizada dessa forma.

O Entrevistado declara ainda que após esse primeiro contato com o RPG em uma disciplina no curso de graduação ele passou a jogar para se apropriar da linguagem:

[...] para me apropriar do que é o RPG eu reuni um grupo de amigos, passei a ler os livros-jogo, os títulos de RPG, para entender melhor como funcionava e passei a experimentar "mestrar"g RPG [...]. E aí eu comecei a experimentar em ambientes fora da sala de aula, comecei a experimentar como jogador casual por questões lúdicas, de prazer, reunir os amigos. Passei a experimentar desde 2010 também, sempre que eu tenho um tempinho reúno a galera para jogar RPG (ENTREVISTA 1, 2017).

Este é mais um dado obtido através das entrevistas que se torna extremamente relevante para análise da experiência do docente: mesmo após o contato inicial com o jogo para fins pedagógicos, afirma a importância de se praticar o hobby como um elemento lúdico, de entretenimento, pois considera essencial que os professores-jogadores pratiquem o jogo. O que faz sentido, já

\footnotetext{
9 A palavra "mestrar" é uma forma coloquial entre os praticantes do hobby de identificar a ação do narrador, também chamado de "mestre" do jogo. Mesmo ainda sendo um jogador, o narrador tem um papel diferente: o de definir os horizontes da narrativa criada no momento do jogo e de estabelecer uma relação constante entre os jogadores e este mundo delimitado. É ele quem regulamenta e divide a participação dos jogadores, controla os personagens que os jogadores interagem durante a aventura, e apresenta os desafios que serão enfrentados durante a sessão de jogo.
} 
que seria impossível operar o jogo e toda a complexidade de elementos que o constitui sem conhecê-los, mesmo no caso de um RPG que já se proponha pedagógico, que em sua maioria as regras tendem a ser relativamente mais simples em relação às mecânicas do jogo de entretenimento, pois o objetivo final do jogo nesse caso é uma experiência de cunho pedagógico.

Compreender as escolhas realizadas e os caminhos trilhados dos docentes investigados nesse texto é fundamental para perceber como esses elementos se traduzem em práticas pedagógicas ao utilizar o RPG em sala de aula.

A análise então consiste em uma verificação qualitativa da experiência dos docentes entrevistados ao utilizar o RPG nas aulas de história, na elaboração do que foi chamado no texto final da dissertação de mestrado de aula-aventura: a experiência do jogo de RPG aplicado em sala de aula para o ensino da disciplina escolar de história. Algumas das produções recentes identificadas no início do processo de pesquisa foram utilizadas como fonte documental e deram suporte à investigação dos relatos de experiência dos docentes.

Mais ainda que justificar esta prática, os entrevistados elencaram elementos essenciais que são requisitos para os professores elaborarem e aplicarem suas próprias aulas-aventuras. Esses requisitos aparecem em seus relatos como um checklist de conhecimentos, saberes e práticas que precisam ser desenvolvidas, algumas prévias ao início das atividades com o RPG e outras que devem sempre ser revistas e aprimoradas através da experiência docente.

A primeira dessas características é se permitir o erro, o risco. O Entrevistado 2 relata sobre essa possibilidade que o professor precisa estar "disposto a conhecer um novo mundo, a depender do professor. Um professor que nunca conheceu o RPG e quer comprar essa ideia agora, se ele está disposto a conhecer um mundo novo" (ENTREVISTA 2, 2017). A prática do RPG em sala de aula é um salto de fé. Antes de qualquer característica ou recurso que seja requisito para o professor que pretende utilizar o RPG como estratégia didática para as aulas de história, este precisa estar disposto a experimentar, a se reconhecer enquanto o aprendiz que em Freire descobre que "era possível ensinar como tarefa não apenas embutida no aprender, mas perfilada em si, com relação a aprender" (FREIRE, 2016, p. 2627). 
A segunda característica mais importante é também parte do que o Entrevistado 2 relatou no trecho apresentado acima: o professor de história precisa conhecer o RPG, não apenas no sentido teórico, do qual esse texto espera poder funcionar como um indicador de caminhos, mas da prática do jogo que só pode ser obtida através da experiência do mesmo. O Entrevistado 1 também reforça essa característica em sua fala:

Um professor que tem a intenção de utilizar o RPG em sala de aula ele precisa se planejar muito bem. Para se planejar muito bem ele precisa conhecer. Então uma dica é ou você forma um grupo de jogo e vão descobrindo juntos, que foi o que eu fiz, ou procura... tem aí vários clubes e grupos. Procurar um para vivenciar a experiência do RPG. Eu diria que não tem como a gente utilizar o RPG na sala de aula com objetivos pedagógicos sem vivenciar algumas aventuras antes, para se apropriar do... hora como jogador, depois mergulhar nessa coisa de narrar né, de ser o jogador narrador, de 'mestrar' (ENTREVISTA 1, 2017)

Como jogador não-sistemático, o Entrevistado 1 relata sua própria "entrada" nessa experiência com o jogo, o qual ele desconhecia até os primeiros contatos já com o RPG pedagógico durante sua formação:

para me apropriar do que é o RPG eu reuni um grupo de amigos, passei a ler os livros-jogo, os títulos de RPG, para entender melhor como funcionava e passei a experimentar "mestrar" RPG [...]. Porque eu precisava conhecer sistemas de regras, como é que funcionava a ambientação, o contexto das aventuras, o que era um personagem, né? (ENTREVISTA 1, 2017).

Ele também afirma que "o $R P G$, não somente do ponto de vista lúdico, o $R P G$ de entretenimento, como o RPG pedagógico, principalmente o RPG pedagógico, eles demandam a construção de uma expertise". Para o desenvolvimento dessa expertise ele evidencia um certo método, um passo a passo que foi tomado por ele para se habituar com os elementos do jogo, essenciais para que as aulaaventuras possam ser desenvolvidas:

A primeira é pesquisar o RPG em si, enquanto jogo, se apropriar dessa linguagem. Depois começar a pesquisar as relações que já existem entre os vários professores, as várias pesquisas que já dão conta dessa relação entre o ensino de história e o RPG ou a educação e o RPG. Então isso dá algumas pistas de como a gente pode planejar. E aí feito isso, leu essas duas coisas, vivenciou e 
experimentou o RPG lúdico, de entretenimento, começar a planejar (ENTREVISTA 1, 2017).

Identificamos aqui então que, para os professores que pretendem elaborar aulas-aventura e utilizar o jogo de RPG em sala de aula se faz necessário: estar aberto a possibilidade do erro; apropriar-se do jogo de RPG e de seus elementos através de sua prática; investigar e aprofundar-se nas leituras entre RPG e educação.

\section{Considerações finais}

É importante reconhecer, de início, que toda prática possui suas limitações e que elas não se encontram encerradas em si. Dentre essas, é necessário evidenciar que este artigo, em suas limitações, não advoga a existência de receitas e manuais que sejam completos e que permitam $100 \%$ de êxito nessa empreitada. Porém, o objetivo foi constituir um referencial que possa ser útil no exercício da elaboração e aplicação de experiências de jogo de RPG em salas de aula, e que sirvam de elementos capazes de propiciar um constante aprimoramento. Na perspectiva de Freire:

\footnotetext{
Por isso é que, na formação permanente dos professores, o momento fundamental é o da reflexão crítica sobre a prática. É pensando criticamente a prática de hoje ou de ontem que se pode melhorar a próxima prática. O próprio discurso teórico, necessário à reflexão crítica, tem de ser de tal modo concreto que quase se confunda com a prática (FREIRE, 2016, p. 40)
}

Dito isso, é esperado que a partir do ciclo pertinente ao preparo e aplicação de experiências similares, a familiaridade com o método e as características do jogo tragam sempre uma perspectiva positiva, mesmo nos momentos em que a experiência não for proveitosa ou alcançar os objetivos desejados pelo docente, pois só através dessa dinâmica de erros e acertos isto seria possível.

O método de entrevistas e suas peculiaridades, descritos e apresentados aqui, compõe um referencial teórico-metodológico desenvolvido como parte de um todo, que corresponde a experiência do ensino de história em escolas da rede básica. Porém, vale salientar que a pesquisa se limitou a construir um referencial 
sobre o jogo de RPG e sua prática na sala de aula a partir da experiência docente. Logo, não foi verificada a efetividade desses modelos referenciais pois sua validação não foi o objetivo deste texto.

Porém, intenciona-se utilizar os dados apresentados em possibilidades de investigações futuras, trazendo nessa perspectiva um maior aprofundamento dos referenciais teóricos aqui trabalhados; uma outra metodologia de pesquisa baseada na pesquisa-ação em que seja possível elaborar, aplicar, analisar e assim validar ou não o proposto nesse texto, no que diz respeito ao uso do RPG como linguagem aplicada ao ensino e aprendizagem da disciplina escolar de história.

A adoção de linguagens no ensino, também, não pode servir como uma solução mágica para os problemas do professor. É preciso reconhecer que nem todos os professores encontrarão as condições necessárias propostas aqui como requisitos, ou sequer terão intenção de utilizar todos os elementos aqui desenvolvidos, e que isso não configura um limitante em relação à prática. É preciso acreditar que cada docente, em sua especificidade, terá a liberdade de usar o material aqui referenciado da forma que for mais conveniente com a sua realidade profissional.

É também importante ressaltar o papel da formação docente, e a relevância que a escuta permite nesse sentido. Ao dar voz aos atores que praticam o jogo em sala, apresentar seus relatos nesse texto e buscar compreender as suas perspectivas, a intenção foi também valorizar a dimensão profissional do professor de história, enquanto um profissional dotado de sua própria historicidade, um "ser que produz, sente, vive de forma crítica, criativa, sensível, enfim, autor, produtor de saberes e de práticas educativas" (FONSECA, 2012, p. 39). Essa dimensão não deixa de ser também um posicionamento político ante, como já dito em outro momento do texto, os recentes movimentos que buscam diminuir a importância da docência enquanto uma parte autônoma do processo de ensino e aprendizagem nas escolas brasileiras.

Buscou-se, nesse sentido, esclarecimentos sobre o método do uso do RPG em salas de aula de história, que se trata ainda de uma linguagem pouco utilizada se comparada com outros recursos e metodologias de ensino, mas que tem um potencial inegável, perceptível a partir dos relatos docentes explorados nesse 
texto, além da quantidade de pesquisas e práticas que têm se desenvolvido sobre o uso do jogo de RPG no ensino da história.

\section{Referências}

BATISTA, José Roniere Morais; SALDANHA, Ana Alayde. A concepção do RolePlaying Game (RPG) em jogadores sistemáticos. Revista Psicologia, Ciência e Profissão, Brasília, v. 29, n. 4, p. 700-717, 2009.

BRASIL. Medida Provisória no 746, de 22 de setembro de 2016. Institui a Política de Fomento à Implementação de Escolas de Ensino Médio em Tempo Integral, altera a Lei no 9.394, de 20 de dezembro de 1996, que estabelece as diretrizes e bases da educação nacional, e a Lei no 11.494 de 20 de junho 2007, que regulamenta o Fundo de Manutenção e Desenvolvimento da Educação Básica e de Valorização dos Profissionais da Educação, e dá outras providências. Brasília: Presidência da República, 2016.

CARDOSO, Eli Teresa. Motivação escolar e o lúdico: o jogo RPG como estratégia pedagógica para o ensino de história. 2008. Dissertação (Mestrado) - UNICAMP, Campinas, 2008.

CARRETERO, Mario; CASTORINA, José A. Desarrollo cognitivo y educación [II]: procesos de conocimientos y contenidos específicos. Buenos Aires: Paidós, 2012.

FRANCISCO, Ricardo Jeferson da Silva. Os jogos de interpretação de personagens e suas perspectivas no ensino de história. 2011. Dissertação (Mestrado) - UEL, Londrina, 2011.

FREIRE, Paulo. Pedagogia da autonomia: saberes necessários à prática educativa. Rio de Janeiro: Paz e Terra, 2016.

FONSECA, Selva Guimarães. Didática e prática de ensino de história: experiências, reflexões e aprendizados. São Paulo: Papirus, 2003.

FONSECA, Selva Guimarães. SILVA, Marcos. Ensinar história no século XXI: em busca do tempo entendido. Campinas: Editora Papirus, 2012.

GODOY, Arilda Schmidt. Introdução à pesquisa qualitativa e suas possibilidades. Revista de Administração de empresas, São Paulo, v. 35, n. 2, mar./abr. 1995.

MALHEIROS, Bruno Taranto. Metodologia da pesquisa em educação. Rio de Janeiro: LTC, 2011.

MEIHY, José Carlos Sebe B. RIBEIRO, Suzana L. Salgado. Guia prático de história oral: para empresas, universidades, comunidades, famílias. São Paulo: contexto, 2011 
MOURA, Fernanda Pereira de. "Escola Sem Partido": relações entre estado, educação e religião e os impactos no ensino de história. 2016. Dissertação (Mestrado) - UFRJ: Rio de Janeiro, 2016.

PEREIRA, Priscilla Emmanuelle Formiga. RPG e história: o descobrimento do Brasil. 2010. Dissertação (Mestrado) - UFPB: João Pessoa, 2010.

RODRIGUES, Joycimara de Morais. Narração e imaginação: a construção do saber histórico sobre a história e cultura africana e afro-brasileira através do role Playing game. 2014. Dissertação (Mestrado) - UFCE: Fortaleza, 2014.

Recebido em 16 de Março de 2019 Aprovado em 19 de Novembro de 2020 